\title{
Privatizar ou não? Eis a questão: um estudo empírico sobre a rentabilidade das empresas de economia mista e empresas privadas listadas na Bovespa no período de 1995 a $2007^{*}$
}

\author{
Silvania Neris Nossa** \\ Rosimeire Pimentel Gonzaga*** \\ Valcemiro Nossa**** \\ José Francisco Ribeiro Filho***** \\ Aridelmo José Campanharo Teixeira******
}

\begin{abstract}
SumÁrio: 1. Introdução; 2. Revisão da literatura; 3. Metodologia; 4. Resultados e discussões; 5 . Conclusão.
\end{abstract}

Summary: 1. Introduction; 2. Literature review; 3. Methods; 4. Results and discussions; 5. Conclusion.

Palavras-chave: rentabilidade; custo da dívida; tamanho; economia mista; economia privada.

\footnotetext{
* Artigo recebido em set. 2009 e aceito em out. 2010.

** Mestre em ciências contábeis pela Fucape Business School. Coordenadora da Secretaria de Pesquisa da Fucape Business School. Endereço: av. Fernando Ferrari, 1358 - Boa Vista - CEP 29075-010, Vitória, ES, Brasil. E-mail: silvanianossa@uol.com.br.

*** Doutoranda em ciências contábeis pela Faculdade de Economia, Administração e Contabilidade da Universidade de São Paulo (FEA/USP). Endereço: av. Prof. Luciano Gualberto, 908 - FEA 3 — CEP 05508-900, São Paulo, SP, Brasil. E-mail: ropgonzaga@gmail.com.

**** Professor doutor da Fucape Business School. Doutor em controladoria e contabilidade pela USP. Endereço: av. Fernando Ferrari, 1358 - Boa Vista — CEP 29075-010, Vitória, ES, Brasil. E-mail: valcemiro@fucape.br.

****** Professor do Departamento de Ciências Contábeis e Atuariais e do Mestrado em Ciências Contábeis da Universidade Federal de Pernambuco (UFPE). Doutor em ciências contábeis pela FEA/USP. Endereço: rua Leonardo da Vince, 8, casa B — Curado II — CEP 54220-000, Jaboatão dos Guararapes, PE, Brasil. E-mail: francisco.ribeiro@ufpe.br.

$* * * * * *$ Professor doutor da Fucape Business School. Doutor em controladoria e contabilidade pela USP. Endereço: av. Fernando Ferrari, 1358 - Boa Vista - CEP 29075-010, Vitória, ES, Brasil.

E-mail: aridelmo@fucape.br.
} 
KEY Words: profitability; cost of the debt; size; mixing economy; private economy.

O objetivo deste trabalho foi verificar se a rentabilidade das empresas de economia mista é diferente da rentabilidade das empresas privadas, levando-se em consideração o tamanho das empresas e o custo da dívida. Foram analisadas as empresas listadas na Bovespa, compreendendo o período de 1995 a 2007. Os dados foram coletados no software Economática. Assim, procurou-se responder à seguinte questão: as empresas brasileiras de economia mista têm desempenho similar ao das empresas privadas? Para o teste da hipótese empregou-se regressão com dados em painel utilizado como proxy: para a rentabilidade, o Lair (lucro antes do imposto de renda); para o tamanho, o log de ativo; e, para o custo de captação de recursos, o custo da dívida $(\mathrm{Kd})$. No que se refere à diferenciação de rentabilidade entre empresas de economia mista e empresas de economia privada, os resultados encontrados corroboram os achados de estudos anteriores. Observou-se neste estudo que tanto o tamanho quanto o custo da dívida estão relacionados à rentabilidade das empresas, mas o fato de a empresa brasileira ser de economia mista ou privada não interfere em sua rentabilidade.

To privatize or not? Here it is the question: an empirical study on the profitability of the companies of mixing economy and private companies listed in the São Paulo Stock Exchange in the period from 1995 to 2007

The objective of this work is to verify if the profitability of the companies of mixing economy is different of the profitability of the private companies, taking in consideration the size of the companies and the cost of the debt. They had been analyzed the companies listed in the São Paulo Stock Exchange, understanding the period from 1995 to 2007. The data had been collected in software Economática. Thus, it was tried to answer the following question: the Brazilian companies of mixing economy have similar performance to the one of the private companies? For the test of the hypothesis, regression with data in panel was used having as proxy: for the profitability the profit before the income tax, for the size log of asset and for the cost of capitation of resources the cost of the debt. As for the differentiation of profitability between companies of mixing economy and companies of private economy the results corroborate the findings of previous studies. It was observed in this study that as much the size than the cost of the debt is related to the profitability of the companies, but the fact of the Brazilian company to be of mixing or private economy does not intervene with its profitability.

\section{Introdução}

Estudos são realizados em busca de sinais significativos sobre a gestão de recursos. No entanto, não se verifica na literatura unanimidade no que tange 
aos resultados encontrados em pesquisas empíricas aplicadas ao mercado brasileiro. A fundamentação dessas pesquisas se dá devido ao posicionamento da sociedade sobre a gestão de recursos públicos, o que para Martins (2004) levou a um conjunto de medidas de forma que as instituições públicas deveriam espelhar-se no mercado, e isto restringiria a atuação do Estado.

Neste sentido, a visão de que a máquina pública deveria reduzir custos para a melhoria do desempenho das empresas tem levado o governo a abrir mão da gestão das empresas. Batistelli e Ricota (2005), Spicer (2004) e Ventriss (2000 e 2002) destacam em seus estudos que a prática da redução de custos é necessária para a melhoria do desempenho das empresas. Porém, nos últimos tempos, alguns autores têm questionado o processo de redução de custo por meio da privatização e da reestruturação de empresas, considerando várias abordagens. Este tipo de questionamento gera oportunidade para novas pesquisas.

Abrucio (2005) apresenta a trajetória da administração pública no período de 1886 a 2006, da perspectiva dos "erros de condução das reformas e os problemas de gestão", considerando as empresas estatais. Para Arantes, Abrucio e Teixeira (2005), as mudanças ocorridas na estrutura de gestão até 1986 trouxeram benefícios para a administração pública. No entanto, essas mudanças não se efetivaram por completo e a burocratização foi um dos fatores comprometedores do desempenho da gestão pública.

Almeida (1996), Bresser-Pereira (2004) e Salm, Candler e Ventriss (2006) ressaltam que a administração pública sempre fora muito usada como um meio de alocar recursos públicos, mas que a partir da última década do século $\mathrm{XX}$, em muitos países, este cenário vem se transformando, inclusive no Brasil.

Neste contexto, surge a reforma da máquina pública no intuito de reduzir custos para a melhoria do desempenho das empresas, como observado nos trabalhos de Batistelli e Ricota (2005), Spicer (2004) e Ventriss (2000 e 2002). A motivação desse estudo se deu conforme a teoria da delimitação do sistema social, uma vez que a sociedade brasileira propôs e permitiu, por meio de seus representantes e gestores, que fossem privatizadas empresas que estavam sob o controle do governo brasileiro.

Conforme Peci (2007:28), reconhece-se que "há controvérsia entre neoliberais e desenvolvimentistas, conservadores e marxistas etc. sobre a forma e os meios de intervenção do Estado na vida econômica e política, que parece nunca chegar ao fim". No entanto, não se pretende com este estudo debater o melhor cenário político, mas verificar empiricamente se há diferença estatisticamente significante entre o desempenho das empresas de economia mista e o das empresas privadas no mercado acionário brasileiro. 
As controvérsias citadas por Peci (2007) podem ser agravadas pelo cenário no qual os contribuintes dos Estados Unidos são convocados a se tornar sócios de instituições financeiras, que têm em sua carteira papéis podres. Torres (2008:1) destaca que a Federal Deposit Insurance Corporation (FDIC), que é a "entidade responsável por essas garantias, não terá limites para tomar recursos emprestados do Departamento do Tesouro para assegurar esses pagamentos".

No pacote aprovado no dia 1ำ de outubro de 2008 está previsto que o total de US\$ 700 bilhões seja liberado para a compra dos papéis podres das instituições financeiras dos EUA, pelos contribuintes. O projeto foi aprovado. Assim, o secretário do Tesouro, Henry Paulson, deve apresentar as linhas gerais de como serão feitas as compras dos títulos, bem como os modelos utilizados para definir o preço dos papéis que forem adquiridos. Desse modo, o contribuinte americano se torna dono dos papéis, mas "a lei proíbe Paulson de pagar pelos papéis mais do que um banco tiver desembolsado para comprálos" (Torres, 2008:1).

O propósito do projeto é minimizar as perdas para o Tesouro americano e, consequentemente, para os contribuintes, mas vale ressaltar que, ao adquirir os papéis podres, o Tesouro deverá receber ações ordinárias sem direito a voto ou ações preferenciais das instituições que venderem os papéis. Se as entidades não tiverem ações negociadas em bolsa, o Tesouro terá direito a receber títulos de dívida sênior emitidos por essa instituição (Torres, 2008).

Diante do exposto, pode-se verificar a inversão dos cenários, de modo que, se antes as empresas eram privatizadas na busca de melhoria na gestão, atualmente no cenário americano os contribuintes são convocados a socorrer as instituições financeiras para evitar uma quebradeira em cadeia.

Segundo Torres (2008), nos Estados Unidos, para a proteção dos recursos dos contribuintes, a lei pede ainda que a SEC faça um estudo de maneira a avaliar o uso dos padrões atuais de marcação a mercado para as instituições financeiras. A lei pede ainda que a SEC verifique em que medida o uso da marcação a mercado teria contribuído para a falência de bancos em 2008.

No Brasil, para Wilson (1980), o Estado brasileiro deixou de ser um grande produtor, controlador e gestor de serviços públicos para atuar na área de regulação. Porém, mais recentemente, na esteira dos reflexos da crise financeira internacional, o Estado brasileiro assume também um protagonismo anticrise ou, por outra, indutor da demanda agregada, com vistas à geração e manutenção de empregos. Os exemplos mais visíveis são o Programa de Aceleração do Crescimento (PAC), do Governo Federal; e o disposto na Lei no 11.908, de 3 de março de 2009, que autoriza o Banco do Brasil S.A. e a Caixa 
Econômica Federal a constituírem subsidiárias e a adquirirem participação em instituições financeiras sediadas no Brasil, como mais um instrumento para absorver empresas do setor financeiro e de seguros em eventuais dificuldades. Diante do exposto se apresenta a seguinte questão de pesquisa: as empresas brasileiras de economia mista têm desempenho similar ao desempenho das empresas privadas?

Espera-se com o presente estudo contribuir para as questões acerca das diferenças entre o desempenho de empresa de economia mista e empresa privada. Nossas análises restringem-se às empresas de economia mista e privada listadas na Bovespa no período de 1995 a 2007.

\section{Revisão da literatura}

\subsection{Pesquisas empíricas: o desempenho de empresas de economia mista e empresas privadas}

Alguns estudos empíricos foram desenvolvidos com o objetivo de testar a superioridade da performance econômica e financeira entre empresas públicas e privadas, conforme citado por Pinheiro (1996) no quadro 1.

$$
\text { Quadro } 1
$$

Resultados empíricos sobre a eficiência relativa de empresas estatais e privadas

\begin{tabular}{|c|c|c|c|}
\hline Setor & $\begin{array}{l}\text { Empresa estatal } \\
\text { mais eficiente }\end{array}$ & $\begin{array}{l}\text { Resultado ambíguo ou sem } \\
\text { diferenças de eficiência }\end{array}$ & $\begin{array}{l}\text { Empresa privada mais } \\
\text { eficiente }\end{array}$ \\
\hline Eletricidade & $\begin{array}{c}\text { Meyer (1975); } \\
\text { Neuberg (1977); } \\
\text { Pescatrice e Trapani } \\
\text { (1980). }\end{array}$ & $\begin{array}{c}\text { Mann (1970); } \\
\text { Junker (1975); } \\
\text { Spann (1977); } \\
\text { Färe et al. (1985); } \\
\text { Atkinson e Halvorsen (1986). }\end{array}$ & $\begin{array}{l}\text { Shepherd (1966); } \\
\text { Moore (1970); } \\
\text { Peltzman (1971); } \\
\text { Tilton (1973); } \\
\text { De Alessi (1974). }\end{array}$ \\
\hline Coleta de lixo & Píer et al. (1974) & $\begin{array}{l}\text { Hirsch (1965); } \\
\text { Kemper e Quigley (1976); } \\
\text { Collins e Downess (1977) }\end{array}$ & $\begin{array}{c}\text { Kitchen (1976); } \\
\text { Savas (1977); } \\
\text { Pommerehne e Frey (1977); } \\
\text { Stevens (1978); } \\
\text { Edwards e Stevens (1978). }\end{array}$ \\
\hline Água & $\begin{array}{l}\text { Mann e Mikesell } \\
\text { (1971); } \\
\text { Bruggink (1982). }\end{array}$ & Feigenbum e Teeples (1983) & $\begin{array}{c}\text { Hausman (1976); } \\
\text { Morgan (1977); } \\
\text { Crain e Zardkoohi (1978, } \\
\text { 1980). }\end{array}$ \\
\hline
\end{tabular}




\begin{tabular}{|c|c|c|c|}
\hline Setor & $\begin{array}{c}\text { Empresa estatal } \\
\text { mais eficiente }\end{array}$ & $\begin{array}{l}\text { Resultado ambíguo ou sem } \\
\text { diferenças de eficiência }\end{array}$ & $\begin{array}{l}\text { Empresa privada mais } \\
\text { eficiente }\end{array}$ \\
\hline $\begin{array}{l}\text { Serviços de } \\
\text { saúde }\end{array}$ & & Beeker e Sloan (1985) & $\begin{array}{c}\text { Clarkson (1972); } \\
\text { Rushing (1974); } \\
\text { Lindsay (1976); } \\
\text { Frech (1976); } \\
\text { Bays (1979); } \\
\text { Frech (1980); } \\
\text { Bishop (1980); } \\
\text { Frech e Ginsburg (1981); } \\
\text { Finsinger (1982); } \\
\text { Wilson e Jadlow (1982); } \\
\text { Schlesinger e Dorwart (1984). }\end{array}$ \\
\hline $\begin{array}{l}\text { Companhias } \\
\text { aéreas }\end{array}$ & & $\begin{array}{l}\text { Forsyth e Hocking (1980); } \\
\text { Morrison (1981); } \\
\text { Jordan (1982). }\end{array}$ & $\begin{array}{l}\text { Davies (1971); } \\
\text { Davies (1977). }\end{array}$ \\
\hline Ferrovias & & $\begin{array}{c}\text { Caves e Christensen (1980); } \\
\text { Caves (1982). }\end{array}$ & \\
\hline $\begin{array}{l}\text { Instituições } \\
\text { financeiras }\end{array}$ & & Lewin (1982) & Davies (1981) \\
\hline $\begin{array}{l}\text { Serviços contra } \\
\text { incêndios }\end{array}$ & & & Ahlbrecht (1973) \\
\hline $\begin{array}{l}\text { Transporte não } \\
\text { ferroviário }\end{array}$ & & & $\begin{array}{c}\text { Pashigian (1976); } \\
\text { Palmer et al. (1983); } \\
\text { McGuire e Van Cott (1984). }\end{array}$ \\
\hline
\end{tabular}

Fonte: Pinheiro (1996).

Como é possível perceber, as evidências acerca do desempenho de empresas públicas versus o desempenho de empresas privadas são ainda pouco conclusivas. Ressalta-se, conforme quadro 1, que nos setores de saúde, companhia aérea, ferrovias, serviços contra incêndios, transporte não ferroviário e instituições financeiras não se encontraram pesquisas com evidência empírica de que o serviço privado tenha desempenho inferior ao setor público. Isto significa que existem pesquisas com evidências empíricas em diversos países de que, por exemplo, as instituições financeiras privadas são mais eficientes do que as instituições financeiras geridas pelos governantes (quadro 1).

As privatizações e reestruturações de empresas ocorridas no mundo têm sido discutidas por alguns autores e de várias perspectivas. Inicialmente, o propósito dos processos de privatização das empresas foi repassar ao setor produtivo a gestão das empresas, permitindo desta forma a livre concorrência e reduzindo a possibilidade de as empresas sofrerem influências político/par- 
tidárias que possam impedir a continuidade de projetos de longo prazo (Reis, 2006). Ademais, alguns autores apregoam que os governos não têm habilidades de gestão e, consequentemente, as empresas com participação apenas do capital privado possuem melhor desempenho se comparando com as empresas com capital público (La Porta e Lopez-de-Silanes, 1997; Megginson e Netter, 2001; Mota, 2003; Reis, 2006).

Nessa linha, existem algumas abordagens técnicas dominantes, permitindo a classificação dos estudos sobre privatizações em categorias, conforme definidas por Serva (2003), descrita no quadro 2.

Quadro 2

\section{Abordagens técnicas}

\begin{tabular}{|c|c|}
\hline Abordagem & Principais autores \\
\hline $\begin{array}{l}\text { Análises empíricas dos processos de privatizações } \\
\text { focando alguns setores específicos. }\end{array}$ & $\begin{array}{l}\text { Paula (1997); Welch e Molz (1999); Ennes (1995); } \\
\text { Dean, Carlisle e Baden-Fuller (1999); Megginson e } \\
\text { Netter (1999). }\end{array}$ \\
\hline $\begin{array}{l}\text { Avaliação do desempenho dos processos de } \\
\text { privatização, considerando indicadores financeiros, } \\
\text { medida de eficiência econômica, objetivos } \\
\text { governamentais e objetivos dos acionistas focando } \\
\text { a teoria do direito de propriedade. }\end{array}$ & $\begin{array}{l}\text { Molz e Hafsi (1997); Boubakri e Cosset (1998); De } \\
\text { Castro et al. (1996); Andrews e Dowling (1998); } \\
\text { D'Souza e Megginson (1999); Gedajlovic e Shapiro } \\
\text { (1998). }\end{array}$ \\
\hline $\begin{array}{l}\text { Análise das implicações políticas da privatização, } \\
\text { considerando as relações entre estado x setor } \\
\text { privado e questionamentos sobre a melhor estrutura } \\
\text { de propriedade. }\end{array}$ & $\begin{array}{l}\text { Shirley (1999); Voisin (1995); Boyco, Shleifer e } \\
\text { Vishiny (1996). }\end{array}$ \\
\hline $\begin{array}{l}\text { Estudos focando diversos aspectos relacionados } \\
\text { aos processos de privatizações, relacionados a uma } \\
\text { região ou país específico. }\end{array}$ & $\begin{array}{l}\text { Brouthers e Arens (1999); Pinheiro e Schneider } \\
\text { (1995); Nolan e Xiaoqiang (1999); Parker (1999); } \\
\text { Baer (1999); Ramamurti (1999); Labaronne (1998); } \\
\text { Chua (1995); Biondi (1999); Stanbury (1994); } \\
\text { Bernier (1994). }\end{array}$ \\
\hline $\begin{array}{l}\text { Estudos empíricos direcionados aos aspectos } \\
\text { organizacionais e gerenciais das empresas } \\
\text { privatizadas. Estes estudos, apesar de importantes, } \\
\text { são raros e demonstram o estágio embrionário } \\
\text { relacionado a essas questões. }\end{array}$ & Dorado e Molz (1998); Özkaya e Askari (1999). \\
\hline
\end{tabular}

Fonte: Adaptado de Serva (2003).

Entre os trabalhos já realizados, alguns se destacam em função das evidências empíricas encontradas, como La Porta e Lopez-de-Silanes (1997), Megginson e Netter (2001), Mota (2003) e Reis (2006). 
Utilizando dados de 218 processos de privatização, entre 1983 e 1991, ocorridos no México, La Porta e Lopez-de-Silanes (1997) encontraram que, na média, as empresas privatizadas tiveram um aumento no faturamento de $24 \%$, e $33 \%$ do aumento foram atribuídos ao desenvolvimento de atividades produtivas, $57 \%$ a ganhos de produtividade e apenas $10 \%$ foram atribuídos ao aumento real dos preços. Os autores concluíram por meio dos resultados encontrados que o processo de privatização está associado a melhores desempenhos e argumentaram que as empresas privatizadas são mais eficientes se comparadas às empresas públicas.

Megginson e Netter (2001) realizaram uma survey, utilizando os trabalhos existentes na literatura acerca dos processos de privatizações, bem como as principais evidências empíricas encontradas. Os autores lançam o que denominaram como as "Lições advindas das pesquisas sobre privatizações", entre elas: i) as pesquisas analisadas corroboram a hipótese de que as empresas estatais são mais eficientes em detrimento das empresas privadas, dentro da amostra analisada; ii) existem poucas evidências empíricas sobre o efeito das privatizações sobre o consumidor; iii) com relação ao argumento de a privatização culminar em desemprego e redução de salários, ressaltam-se os achados de La Porta e Lopez-de-Silanes (1997) e outros autores, que encontraram aumento do nível de emprego oriundo da privatização.

Considerando as características brasileiras, Mota (2003) analisou a relação custo $\mathrm{x}$ benefícios sociais da privatização e reestruturação do setor de energia elétrica ocorridos no Brasil no período de 1995 a 2000. A autora encontrou que os principais benefícios têm sido significantes, mas são incorporados aos ganhos das empresas, e conclui que os consumidores poderiam ter maiores ganhos com o processo.

Ainda no setor elétrico brasileiro, Reis (2006) verificou empiricamente qual o impacto causado sobre a qualidade dos serviços de distribuição de energia elétrica no Brasil, após as privatizações e reestruturação ocorridas em 14 empresas do setor elétrico brasileiro no período de 1995 a 2000, focando os indicadores técnicos de qualidade de fornecimento de energia elétrica no Brasil. $\mathrm{O}$ autor encontrou indícios de melhora na qualidade da distribuição do serviço de energia elétrica fornecido no Brasil após a privatização das empresas da amostra.

As agências reguladoras surgiram na tentativa de flexibilização da gestão pública para descrever como seria possível controlar as empresas para que não comprometessem o fornecimento de recursos para a sociedade ao privatizá-las? Neste sentido, Fachin (1998), Fadul (1998), Fischer, Teixeira, e Heber (1998) e Peci (2002 e 2007) ressaltam que "a criação das agências 
reguladoras não resultou de uma discussão quanto ao modelo de regulação". Inclusive ressaltam que "as reformas não foram baseadas num amplo consenso na sociedade civil, conforme indicavam as experiências de outros países".

Nesse contexto de desestatização e tentativas de reformas gerenciais, é redefinido o papel do Estado, qualificando-o mais como regulador do que como indutor do processo de desenvolvimento do país. Paralelamente — mas não articuladamente é enfatizada a importância de uma flexibilização da ação pública, propondo-se um conjunto de medidas uniformizadoras inspiradas na Nova Gestão Pública (New Public Management), que visam dar ao administrador público mais autonomia gerencial, numa tentativa de tornar a administração pública mais parecida com a administração de empresas: o chamado movimento de agencificação (Peci, 2007:14).

Para Peci (2007), a primeira geração de agências reguladoras abrange o período 1995-1998 e caracteriza-se pela criação das chamadas agências reguladoras de infraestrutura, como a Agência Nacional de Energia Elétrica (Aneel), Agência Nacional de Telecomunicações (Anatel) e Agência Nacional de Petróleo (ANP). No período de 1999/2000 foram criadas a Agência Nacional de Vigilância Sanitária (Anvisa), a Agência Nacional de Saúde Suplemen$\operatorname{tar}$ (ANS) e a Agência Nacional de Água (ANA). Em 2001/02 foram criadas a Agência Nacional do Cinema (Ancine), a Agência Nacional de Transportes Terrestres (ANTT) e a Agência Nacional de Transportes Aquaviários (Antaq).

Melo (2002) defende que as agências apresentam propósitos diferentes, tais como: a regulação de monopólios naturais, a correção de falhas de mercado, a presença de externalidades, a solução de problemas de coordenação e a redução de possíveis conflitos de interesses.

De acordo com Jensen e Meckling (1976), na teoria do agente, a gestão de recursos públicos por políticos em benefício próprio pode ser uma prática que pode corroer os resultados da instituição ou mesmo corroer a estrutura da organização. A opção por um projeto que não tenha valor presente líquido positivo, mas que pode maximizar a riqueza pessoal do gestor indiretamente. Essa pode ser uma prática que, para Watts (2003a), pode ser contornada com a redução de recursos nas mãos dos gestores de má-fé, o que poderia reduzir o risco de expropriação. A essência do problema de agência é o conflito de interesses, possibilitado pela propriedade e controle. Para Scott (1998, apud Gomes, 2006), o ambiente se ajusta às pressões sociais e culturais, e isto faz parte da teoria institucional. Para Salm, Candler e Ventriss (2006), de acordo com a teoria da delimitação do sistema social, a sociedade é humana e por isso 
"é mais do que uma conta econômica criatura". Por isso a sociedade é capaz de realizações pessoais, podendo inclusive influenciar no mercado.

Fadul (1997) destaca alguns fatores que podem levar os gestores públicos a buscarem a privatização, por exemplo: as reestruturações econômicas e sociais, as mudanças nos modos de vida e nos padrões de consumo, dever de atender, com recursos orçamentários limitados, às demandas que se ampliam, bem como a evolução de múltiplos fatores (internacionalização, comunicações ultrarrápidas, desenvolvimento da mídia, exigências crescentes das populações e outros) que reduzem, cada vez mais, a capacidade de governar. Fadul (1997:56) destaca ainda que "quase todos os países ocidentais buscam maior eficiência e produtividade dos serviços públicos e melhor atendimento aos cidadãos".

No Brasil, as empresas de economia mista são geridas por três órgãos distintos da administração pública federal: a) Ministério da Fazenda (MF), por meio da STN, com relação à Assembleia Geral de Acionistas (Decretos nos 1.091/1994 e 2.673/1998); b) Ministério de Planejamento, Orçamento e Gestão (MPOG), por meio do Dest, em relação ao planejamento, orçamento e pessoal (Decreto ํㅡㄴ 3.735/2001); e c) Ministério supervisor, em relação à gestão do negócio corporativo. Há ocasiões nas quais a Casa Civil se pronuncia (Antunes et al., 2008).

Neste sentido, Jensen e Mecking (1976) ressaltam que há conflito de interesse em qualquer forma de delegação de decisão. O principal motivo consiste na dissociação dos custos e benefícios da tomada de decisão. Segundo Antunes e colaboradores (2008:3), “ao delegar poder de decisão, a União transfere ao gestor a responsabilidade sobre o desempenho da empresa, mas a União continua sendo a maior beneficiada por esse desempenho".

Para Antunes e colaboradores (2008), tanto as empresas públicas quanto as empresas privadas têm problemas de agência devido à separação entre propriedade e controle. As estatais federais apresentam fatores adicionais de complexidades que tornam a governança mais necessária do que para empresas privadas, quais sejam: a) indicação política para membros dos órgãos de administração; b) interesses diversos que não somente maximização de lucros; e c) diretrizes de acionista controlador definidas por três ministérios (Ministério da Fazenda, Ministério de Planejamento, Orçamento e Gestão e Ministério Supervisor).

O meio acadêmico tem discutido duas perspectivas distintas acerca do papel das organizações. Para Friedman (1970), a economia clássica defende que as organizações existem para maximizar valor para o acionista (expectativa dos shareholders). Por outro lado, a teoria dos stakeholders defende que as organizações existem para atender à demanda de um grupo maior e mais 
abrangente de atores sociais, entre eles, os acionistas, o corpo diretivo, o corpo funcional, o conjunto de fornecedores, clientes e governos (Freeman, 1984).

Nas duas últimas décadas do século XX, inúmeras nações buscaram na privatização um meio para reduzir a probabilidade de a gestão das empresas de economia mista ser contaminada pela gestão de políticos, conforme Jensen e Meckling (1976). No entanto, na contramão, segundo Torres (2008), nos Estados Unidos os contribuintes são convocados a salvar instituições financeiras no intuito de evitar uma quebradeira em cadeia. Para salvar as instituições financeiras os contribuintes americanos compram papéis "podres" dos bancos nos EUA, no máximo ao preço de custo, ou seja, o preço que os bancos pagaram pelos ativos "podres".

Representando os contribuintes americanos:

Quando tiver adquirido boa parte dos papéis relacionados a hipotecas disponíveis no mercado, o Tesouro deverá tentar renegociar as condições desses financiamentos com os mutuários, podendo reduzir tanto o principal quanto as taxas de juros, mas assegurando que os contribuintes (agora detentores indiretos dos recebíveis das hipotecas) não percam dinheiro (TORRES, 2008:1).

O conflito de interesses entre os contribuintes e os sócios das instituições financeiras é esperado na medida em que:

as instituições que venderem títulos podres para o Tesouro deverão concordar em reduzir os programas de recompensa dos seus altos executivos. Estará proibido o pagamento de grandes volumes de recursos para executivos que deixarem as empresas (paraquedas dourado) durante o período em que o Tesouro detiver ações ou dívida da instituição (TORRES, 2008:2).

Assim, Markowitz (1952) defende a privatização em sua argumentação de que a pulverização dos recursos da União em diversas empresas reduz a exposição do portfólio público ao risco sistemático da economia. Esses aspectos positivos da delegação de poderes da União para os gestores podem ser superiores aos custos de agência de Jensen e Meckling (1976), tornando assim viável e relevante à observação empírica.

O Senado dos EUA autoriza que a Securities and Exchange Commission (SEC) suspenda a obrigação de marcação a mercado do valor dos ativos, nos termos do pronunciamento 157 emitido pelo Financial Accounting Standards Board (Fasb - comitê de padrões contábeis dos EUA), se ela entender "que é neces- 
sário ou apropriado para o interesse público e consistente com a proteção dos investidores" (Torres, 2008:1).

No Brasil pode ser que intuitivamente a sociedade brasileira tenha se proposto a reduzir o risco de gestão de recursos públicos ao retirar dos governantes a gestão dos recursos públicos. No entanto, não se sabe se há diferença entre os resultados alcançados pelas empresas públicas e privadas no período de 1995 a 2007, levando-se em consideração todos os setores que passaram por privatização. Não se pretende com esta pesquisa exaurir o estudo do tema, nem mesmo declarar nossa simpatia pela gestão pública ou privada por meio desta, mas testar empiricamente o desempenho da gestão pública e da gestão privada.

\subsection{Pesquisas empíricas: a relação do custo da dívida (kd) e do tamanho da empresa com a lucratividade}

Este tópico se propõe a apresentar estudos destacados na revisão da literatura que discutem as variáveis custo da dívida e o tamanho das empresas como variáveis explicativas ou não para a lucratividade das empresas.

\subsubsection{Tamanho da empresa e a lucratividade}

No contexto econômico, Bain e Mason (1953, apud Porter, 1991) definiram desempenho como lucratividade, ou seja, a eficiência na alocação de recursos, eficiência técnica, por meio da minimização de custos e conduta inovadora. Segundo Brito e Brito (2005), em 1931, na pesquisa de Gibrat, intitulada Les inégalities économiques, foi apresentada a chamada "lei de Gibrat", que se propunha a estudar a lei do efeito proporcional, que seria o estudo do efeito tamanho das empresas e a distribuição de renda entre indivíduos.

Em suas pesquisas, Dalmácio e colaboradores (2005), Gupta (1980), Sutton (1997), Bain e Mason (1968, apud Porter, 1991), Kalecki (1945) e Hall (1987) encontraram relação positiva entre o tamanho e a lucratividade das empresas. Não encontraram evidências empíricas estatisticamente significativas entre o tamanho e a lucratividade das empresas os trabalhos de Besanko e colaboradores (2004, apud Brito e Brito, 2005), Sign e Whittington (1975, apud Brito e Brito, 2005), Kumar (1981) e Ricketts (2002, apud Brito e Brito, 2005).

Porter (1991:144) ressalta que "as empresas que tenham parcelas de mercado relativamente pequenas terão menor potencial de lucro" em compa- 
ração com as empresas com maior potencial de lucro. Inclusive, o autor ressalta que tais empresas "gozam de graus diferentes de negociação com clientes e fornecedores". Assim, as empresas maiores vendem mais e seus custos dos produtos são mais reduzidos.

\subsubsection{A Lucratividade}

Piotroski (2000), Gitman (2002), Matarazzo (2003) e Lopes e Galdi (2006), entre outros autores, utilizaram o ROA como proxy para a lucratividade das empresas. Para Gitman (2002:123), o retorno sobre o ativo "mede a eficiência global da administração na geração de lucros com seus ativos disponíveis. Quanto mais alta for essa taxa melhor".

Nesta pesquisa foi utilizado como proxy para desempenho o índice de lucratividade das empresas da amostra, medido pelo Lair (Lucro Antes do Imposto de Renda) em t, em razão do Patrimônio Líquido do período anterior (t-1). Utilizou-se o Lair em detrimento ao Lucro Líquido pelo fato de que as empresas têm métodos e benefícios no pagamento do Imposto de Renda, assim como possuem despesas com juros diversos (Paste, 2006).

\subsubsection{Custo da dívida (KD) e a lucratividade}

As empresas podem obter recursos de diversas fontes: capital de terceiros (endividamento), capital próprio (emissão de ações) ou reinvestimento de lucros (retenção de lucros). Cada empresa opta por formas diferentes de captação. A forma de captação de recursos pode influenciar no custo, pois cada tipo de captação tem um custo específico para a firma, o chamado custo de captação de recursos ou custo da dívida, que reflete o retorno exigido pelos fornecedores de capital (Schroeder et al., 2005).

Para Marcon (2002), o custo da dívida está relacionado à forma pela qual as empresas captam recursos, de diferentes fontes, praticando diversas taxas e com diferentes riscos. O retorno exigido pelos investidores, tratandose de capital próprio, ou por intermediários financeiros, no caso de capital de terceiros, que determina o custo de capital.

Neste sentido, Modigliani e Miller (1958) defendem que empresas inseridas em ambiente com diversificada forma de captação de investimentos contemplem retornos incertos. Assim, os autores propuseram uma estrutura de capital "ótima", na qual apresentam o trade off entre os custos e benefícios do endividamento. 
Nesta linha de estudo, Myers (1984) argumentou que as firmas adotam a teoria de hierarquização das fontes de financiamento (The pecking order Theory): recursos próprios, endividamento e emissões de ações. Ressalta-se, de acordo com o Valor Online (2008), que o sr. Jorge Simino, diretor de investimento da Fundação Cesp, declarou em entrevista ter recebido muitas consultas de companhias sobre preços e prazos para a emissão de debêntures ou captação no mercado local de empréstimos em substituição à emissão de ações devido às turbulências provocadas pela crise imobiliária dos EUA. O Valor Online (2008) declarou ainda que a "falta de dinheiro na praça, em meio à crise de crédito internacional, forçou as companhias brasileiras a buscar alternativas para escapar do aperto ou cancelar suas operações". As empresas descritas por Valor Online (2008) são: Lojas Renner, Localiza Rent a Car, Visanet, Vivo e Banco do Brasil.

\subsubsection{Lucratividade: tamanho e custo da dívida}

Entre os estudos que buscaram analisar as estruturas de capital das firmas, destaca-se o trabalho de Titman e Wessels (1988), no qual os autores verificaram a estrutura de capital das empresas americanas e encontraram evidências empíricas de que há relação entre nível de endividamento de longo prazo, rentabilidade e tamanho nas empresas americanas. Pomerleano e Zhanh (1999), ao estudarem as empresas de países latino-americanos e asiáticos, encontraram uma relação negativa entre nível de endividamento de curto e longo prazo, rentabilidade e tamanho das empresas.

No Brasil existem alguns estudos acerca da estrutura de capital das empresas brasileiras. Destaca-se a pesquisa de Brito e Lima (2005), que analisaram a estrutura de capital de empresas brasileiras, no período de 1995 a 2001, e concluíram que as empresas privadas se endividam mais do que as empresas de controle público e as empresas estrangeiras. Lopes e Alencar (2008) investigaram a relação do nível de disclosure com o custo de capital das empresas brasileiras listadas na Bovespa no período de 1998 a 2005. Os autores encontraram evidências de que no Brasil o nível de disclosure realizado pelas empresas afeta o custo de capital das mesmas.

\section{Metodologia}

O objetivo deste trabalho concentrou-se em verificar empiricamente se o desempenho de empresas de economia mista é diferente do desempenho de 
empresas privadas. Para atender ao objetivo proposto testou-se a seguinte hipótese: h0 - O desempenho de empresas de economia mista é diferente do desempenho de empresas privadas.

Para o teste da hipótese descrita, utilizaram-se como amostra as empresas de economia mistas e privadas listadas na Bolsa de Valores de São Paulo (Bovespa), compreendendo o período de 1995 a 2007.

As empresas denominadas de economia mista nesse estudo são as empresas nas quais há participação do estado e da iniciativa privada em sua estrutura de capital. Assim, participaram dos testes estatísticos 899 observações com informações disponíveis, após a exclusão de $2 \%$ de outliers superiores e $2 \%$ de outliers inferiores. Sobre as empresas que foram privatizadas, observou-se a data da privatização, conforme Brasil (2008), para estabelecer o momento a partir do qual as empresas deixaram de ser de economia mista tornando-se privadas, contendo em sua estrutura de capital apenas a participação da iniciativa privada.

Como empresas privadas foram consideradas aquelas que só continham participação da iniciativa privada em sua estrutura de capital.

Utilizou-se a técnica de dados em painel com efeito fixo, sendo sua necessidade verificada por meio da aplicação do teste Hausman que, segundo Greene (1997) e Wooldridge (2006), se propõe a testar se os coeficientes do painel com efeitos fixos e efeitos aleatórios são sistematicamente diferentes (Nossa, 2007).

Foi utilizado como proxy para desempenho o índice de lucratividade das empresas da amostra, medido pelo Lair (lucro antes do imposto de renda) em t, em razão do Patrimônio Líquido do período anterior, ou seja, em t-1. Utilizou-se o Lair em detrimento ao lucro líquido pelo fato de que as empresas têm métodos e benefícios no pagamento do Imposto de Renda, assim como possuem despesas com juros diversos (Paste, 2006).

Para observar a existência de diferenças de desempenho entre empresas de economia mista e privadas, utilizou-se como independente a variável dummy assumindo valor um para a empresa de economia mista e zero para a empresa privada. Foram utilizadas ainda as variáveis explicativas $\mathrm{KD}$ - cost of debt, representando o custo de captação de recurso da empresa, utilizado como proxy para risco e Log Ativo como proxy para tamanho. O uso das variáveis Kd e tamanho se justifica, uma vez que, caso essas variáveis estejam relacionadas com a variável dependente, não seja introduzido viés aos resultados da estatística de regressão em painel. Assim, as variáveis Kd e tamanho representam variáveis de controle para amenizar o termo de erro de regressão. 
A variável tamanho, definida pelo logaritmo de ativo, foi utilizada como variável de controle pelo fato de que empresas com maiores ativos podem apresentar maiores rentabilidades, conforme Dalmácio e colaboradores (2005), Gupta (1980), Sutton (1997), Kalecki (1945) e Hall (1987), que encontraram evidências de que o tamanho da empresa está relacionado com a lucratividade.

Utilizou-se o Kd como proxy para o controle do risco inerente à captação de recursos, sendo utilizado para segregar o risco inerente às firmas.

Para o teste da hipótese proposta foi utilizada a seguinte equação de regressão:

$\mathrm{LR}_{\mathrm{t}, \mathrm{i}}=\beta_{1+} \beta_{2} \mathrm{D}_{\mathrm{i}, \mathrm{t}}+\beta_{3} \mathrm{KD}_{\mathrm{i}, \mathrm{t}}+\beta_{4}$ Logativo $_{\mathrm{i}, \mathrm{t}}+e$

Onde:

$\mathrm{LR}_{\mathrm{t}, \mathrm{i}}=$ Proxy para desempenho, Lair da firma i no período t, em razão do Patrimônio Líquido da firma i no período t-1;

$\mathrm{D}_{\mathrm{i}, \mathrm{t}}=$ Variável dummy, que assume o valor 0 quando a empresa for de economia mista e 1 quando a empresa for privada;

$\mathrm{KD}_{\mathrm{i}, \mathrm{t}}=$ Controle por Custo da Dívida, medido pela despesas financeiras da firma i no período t, em razão da dívida total (Debêntures de curto e longo prazo + Financiamento de curto e longo prazo + fornecedores);

Logativo $_{\mathrm{i}, \mathrm{t}}=$ Controle por Tamanho, medido pelo logaritmo do total de ativo da firma I no período t.

\section{Resultados e discussões}

Os resultados descritos a seguir são advindos da regressão estimada em painel no Stata 9.0, observando os pressupostos de regressão, sendo utilizada a técnica de painel com efeito fixo e com o uso da ferramenta robust.

Tabela 1

Resultados encontrados

\begin{tabular}{|lccc|}
\hline \multicolumn{4}{|c|}{ Estatística de Regressão em Painel - Efeito Fixo } \\
\hline \multicolumn{4}{|c|}{$\mathrm{LR}_{\mathrm{t}, \mathrm{i}}=\beta_{1+} \beta_{2} \mathrm{D}_{\mathrm{i}, \mathrm{t}}+\beta_{3} \mathrm{KD}_{\mathrm{i}, \mathrm{t}}+\beta_{4}$ Logativo $_{\mathrm{i}, \mathrm{t}}+\mathrm{e}$} \\
\hline$\beta_{2} \mathrm{D}$ & Coeficientes & Estatística $-\mathrm{t}$ & P-value \\
$\beta_{3} \mathrm{KD}$ & -0.4335 & -1.38 & 0.169 \\
$\beta_{4}$ Logativo & -0.0000 & -2.41 & $0.016 * *$ \\
& 0.0953 & 2.66 & $0.008 *$ \\
\hline
\end{tabular}




\begin{tabular}{|lccc|}
\hline \multicolumn{4}{|c|}{ Estatística de Regressão em Painel - Efeito Fixo } \\
\hline \multicolumn{4}{|c|}{$\mathrm{LR}_{\mathrm{t}, \mathrm{i}}=\beta_{1+} \beta_{2} \mathrm{D}_{\mathrm{i}, \mathrm{t}}+\beta_{3} \mathrm{KD}_{\mathrm{i}, \mathrm{i}}+\beta_{4}$ Logativo $_{\mathrm{i}, \mathrm{t}}+\mathrm{e}$} \\
\hline & Coeficientes & Estatística $-\mathrm{t}$ & P-value \\
\hline$\beta_{1}$ & -2.39 & $0.0177^{* *}$ \\
\hline $\mathrm{R}^{2}$ ajustado & -1.2129 & 0.0302 \\
№ Observações & & 899 \\
Prob > F & & 0.0116 \\
\hline
\end{tabular}

Nota: onde: ${ }^{*}{ }^{* *}$ Estatisticamente significantes ao nível de 1\% e 5\%, respectivamente;

$\mathrm{LR}_{\mathrm{t}, \mathrm{i}}=$ Proxy para desempenho, Lair da firma i no período t, em razão do Patrimônio Líquido da firma i no período t-1; $\mathrm{D}_{\mathrm{i}, \mathrm{t}}=$ Variável dummy, que assume o valor 0 quando a empresa for de economia mista e 1 quando a empresa for privada;

$\mathrm{KD}_{\mathrm{i}, \mathrm{t}}=$ Controle por Custo da Dívida, medido pela despesas financeiras da firma i no período t, em razão da dívida total (Debêntures de curto e longo prazo + Financiamento de curto e longo prazo + fornecedores); Logativo $_{i, t}=$ Controle por Tamanho, medido pelo logaritmo do total de ativo da firma I no período $\mathrm{t}$.

Os resultados demonstram que não há indícios de diferença entre o desempenho de empresas de economia mista e privada, verificado por meio da não significância estatística da variável dummy, ao nível de significância de 5\%, cujo p_valor é 0,169 (tabela 1), admitindo-se zero para empresas de economia mista e um para empresas privadas.

Os resultados encontrados indicam que, das variáveis explicativas estudadas na busca de explicação para o lucro, o tamanho está relacionado com o desempenho da gestão. No entanto, o fato de a gestão ser pública ou privada não apresenta resultado estatisticamente significativo. O resultado encontrado neste artigo corrobora aqueles encontrados por Man (1970), Junker (1975), Spann (1977), Fare e colaboradores (1985), Atkinson e Halvorsen (1986), Hirsch (1965), Kemper e Quigley (1976), Collins e Downess (1977), Feigenbum e Teeples (1983), Beeker, Sloan Forsyth e Hocking (1980), Morrison (1981), Jordan (1982), Caves e Christensen (1980), Caves (1982), Lewin (1982), citados por Pinheiro (1996), de que não há relação do lucro das empresas com o fato de a empresa ser de economia mista ou privada.

No entanto, verificou-se que existe relação positiva entre o tamanho da empresa e o lucro auferido no período de 1995 a 2007. Este resultado corrobora com aqueles encontrados por Gupta (1980), Sutton (1997), Kalecki (1945), Hall (1987), Porter (1991) e Dalmácio e colaboradores (2005), que encontraram evidências de que o tamanho da empresa está relacionado com a lucratividade.

Este estudo corrobora ainda com os achados de Titman e Wessels (1988), uma vez que o custo da dívida está negativamente relacionado ao 
desempenho das empresas brasileiras listadas na Bovespa no período de 1995 a 2007. Assim, na medida em que o custo da dívida aumenta, a lucratividade das empresas diminui, mas independente das empresas serem de economia mista ou privada. Diante do exposto, a hipótese de que o desempenho das empresas de economia mista é diferente do desempenho das empresas privadas é rejeitada ao nível de significância de 5\%.

\section{Conclusão}

Este estudo objetivou verificar se a rentabilidade das empresas de economia mista é diferente da rentabilidade das empresas privadas. Para a verificação do objetivo proposto foram selecionadas as empresas listadas na Bovespa no período de 1995 a 2007.

Em pesquisas anteriores não se verifica unanimidade no que se refere aos resultados encontrados em pesquisas empíricas, aplicadas no mercado brasileiro, sobre a gestão pública ou privada. Por um lado, resultados de pesquisas como a de Batistelli e Ricota (2005), Spicer (2004) e Ventriss (2000 e 2002) defendem que a redução de custos pode levar à melhoria do desempenho das empresas e uma das formas de reduzir custos seria a privatização. Por outro lado, o resultado das pesquisas de Almeida (1996), Bresser-Pereira (2004) e Salm, Candler e Ventriss (2006) são de que a administração pública tem sido meio de alocar recursos públicos, de acordo com o interesse dos gestores, mas destacam os pesquisadores que este cenário vem se transformando, inclusive no Brasil.

A motivação deste estudo se dá conforme Jensen e Mecling (1976), no que se refere à teoria do agente, para investigar o desempenho de empresas na gestão de recursos públicos e privados. Outro fato motivador para esta pesquisa é que no mercado internacional as empresas foram privatizadas na busca de melhoria de seu desempenho; no entanto, os contribuintes foram convidados a resgatá-las para evitar a quebra dessas empresas.

$\mathrm{Na}$ literatura destacam-se os estudos que encontraram relação positiva entre o desempenho e o tamanho das empresas: Bain e Mason (1953, apud Porter, 1991), Dalmácio e colaboradores (2005), Gupta (1980), Sutton (1997), Bain e Maison (1968, apud Porter, 1991), Kalecki (1945) e Hall (1987). No que se refere ao estudo do custo da dívida e sua relação com a lucratividade destacam-se as pesquisas de Schroeder e colaboradores (2005), Marcon (2002), Modigliani e Miller (1958) e Myers (1984). O estudo da relação de variáveis, tais como tamanho e custo da dívida e desempenho das em- 
presas, em pesquisas anteriores, gera uma expectativa em relação ao resultado esperado neste estudo. O resultado esperado é de que: no que se refere ao tamanho, quanto maior o tamanho da empresa maior a lucratividade, devido ao poder sobre fornecedores, clientes etc., e no que tange ao custo da dívida, espera-se que o custo da dívida tenha relação inversa com a lucratividade.

Por meio da análise de regressão em painel, conclui-se que existe relação inversa entre o custo da dívida e o desempenho das empresas. Assim, quanto mais as empresas se endividam, pior é sua rentabilidade. No que se refere ao tamanho, encontrou-se relação positiva com o desempenho das empresas. Verificou-se, ainda, que o desempenho das empresas não difere entre empresas de economia mista e empresas privadas.

Os resultados encontrados não apresentam evidências de que a empresa pública tem melhor desempenho do que a empresa privada ou ainda que a empresa privada tenha melhor desempenho do que a empresa pública. Destaca-se uma limitação imposta pelos dados analisados, uma vez que o número de empresas de economia mista é pequeno se comparado ao número de empresas privadas. Desse modo, não se pode aplicar, em princípio, outros testes levando-se em consideração o setor no qual as empresas estão inseridas. Recomenda-se que em futuras pesquisas sejam elaborados testes, no que se refere aos retornos para os acionistas no mercado acionário. Recomenda-se, ainda, que em futuras pesquisas seja estudado o desempenho de empresas públicas e privadas com recorte em países e em setores mais e menos regulados.

\section{Referências}

ABRUCIO, F.L. A cooperação federativa no Brasil: a experiência do período FHC e os desafios do governo Lula. Revista de Sociologia Política, Curitiba, n. 24, p. 4167, jul. 2005.

ALMEIDA, H.T. de. Pragmatismo por necessidade: os rumos da reforma econômica no Brasil. Dados, n. 39. p. 213-234, 1996.

ANTUNES, G.A. et al. Instrumentos contábeis de proteção aos recursos públicos investidos nas sociedades de economia mista: uma investigação empírica. In: CONGRESSO USP DE CONTROLADORIA E CONTABILIDADE, 8ㅜㅗ 2008, São Paulo, 2008. Anais...

ARANTES, R.B.; ABRUCIO, F.L.; TEIXEIRA, M.A.C. A imagem dos tribunais de contas subnacionais. Revista do Serviço Público, Brasília, v. 56, n. 1, p. 57-85, 2005. 
BALL, R.; BROWN, P. An empirical evaluation of accounting income numbers. Journal of Accounting Research, v. 6, n. 2, p.159-178, 1968.

BATISTELLI, F.; RICOTA, G. The rhetoric of management control in italian cities. Constructing new meanings of public action. Administration and society, n. 36, p. 661-687, 2005.

BRASIL. Ministério do Desenvolvimento Indústria e Comércio. Privatização no Brasil. Disponível em: <www.bndes.gov.br/conhecimento/publicacoes/catalogo/ Priv_Gov.pdf >. Acesso em: 20 set. 2008.

BRESSER-PEREIRA, L.C. Democracy and public management reform. New York: Oxford University Express, 2004.

BRESSER-PEREIRA, L.C. Reforma do Estado para a cidadania. São Paulo: 34, 1998.

BRITO, L.A. Ledur; BRITO, E.P. Zamith. Tamanho e desempenho financeiro. In: ENANPAD, XXIX, 2005, Brasília. Anais...

BRITO, R.D.; LIMA, M.R. A escolha da estrutura de capital sob fraca garantia legal: o caso do Brasil. Revista Brasileira de Economia, Rio de Janeiro, v. 59, n. 2, abr./jun. 2005.

CAMARGOS, M.A.; BARBOSA, F.V. Fusões, aquisições e takeovers: um levantamento teórico dos motivos, hipóteses testáveis e evidências empíricas. Caderno de Pesquisas em Administração, São Paulo, v. 10, n. 2, p.17-38, abr./jun. 2003.

DALMÁCIO, F.Z. et al. Relação entre a teoria da estratégia do posicionamento e parâmetros das demonstrações contábeis: uma aplicação no mercado brasileiro. In: CONGRESSO USP, 5o, 2005, São Paulo. Anais...

FACHIN, R.C. Reforma do Estado e agências de regulação: o caso do Rio Grande do Sul. In: SEMINÁRIO INTERNACIONAL SOBRE REESTRUTURAÇÃO E REFORMA DO ESTADO: BRASIL E AMÉRICA LATINA NO PROCESSO DE GLOBALIZAÇÃO, 1998, São Paulo. Anais...

FADUL, E.M.C. Reforma do Estado e serviços públicos: transformação de um modelo ou adaptação a uma nova ordem social? In: SEMINÁRIO INTERNACIONAL SOBRE REESTRUTURAÇÃO E REFORMA DO ESTADO: BRASIL E AMÉRICA LATINA NO PROCESSO DE GLOBALIZAÇÃO, 1998, São Paulo. Anais...

FADUL. E.M.C. Redefinição de espaços e papéis na gestão de serviços públicos: fronteiras e funções da regulação social. RAC, v. 1, n. 1, p. 55-70, jan./abr. 1997.

FISCHER, T.; TEIXEIRA, E.; HEBER, F. Estratégias de gestão e reconfiguração organizacional: os setores de energia elétrica e telecomunicações. Revista de Administração Pública, Rio de Janeiro, v. 32, n. 3, p. 9-28, maio/jun. 1998. 
FREEMAN, R.E. The politics of stakeholders theory: some future directions. Business Ethics Quarterly, v. 4, n. 4, p. 409-422, Oct. 1984.

FRIEDMAN, M. The social responsibility of business is to increase its profits. The New York Times Magazine, Sept. 13, 1970.

GITMAN, L.J. Princípios de administração financeira. 7. ed. São Paulo: Harbra, 2002.

GOMES, R.C. Stakeholder management in the local government decision-making area: evidences from a triangulation study with the English local government (1). $R A C$, edição especial, p. 77-98, 2006.

GREENE, William H. Econometric analysis. 3. ed. New Jersey: Prentice-Hall. 1997.

GUPTA, N. Some alternative definitions of size. The academy of management journal, v. 23, n. 4, p. 759-766, 1980. Disponível em: <www.jstor.org/journals/aom. html>. Acesso em: 9 jun. 2006.

HALL, B.H. The relationship between firm size and fir growth in the U.S. manufacturing sector. The Journal of Industrial Economics, v. 35, n. 4, p. 583-606, 1987. Disponível em: <www.jstor.org/journals/aom.html>. Acesso em: 9 jun. 2006.

JENSEN, M.C.; MECKLING, W.H. Theory of firm: managerial behavior, agency costs and ownership structure. Journal of Financial Economics, v. 3, n. 4, p. 305360, 1976.

KALECKI, M. On the Gibrat distribution. Econometrica, v. 13, n. 2, p. 161-170, 1945. Disponível em: <www.jstor.org/journals/aom.html> Acesso em: 9 jun. 2006.

KLOECKNER, G.O. Fusões e aquisições: motivos e evidência empírica. Revista de Administração, São Paulo, v. 29, n. 1, p. 42-58. jan./mar. 1994.

KUMAR, M.S. Growth, acquisition activity and firm size: evidence from the United Kingdom. The Journal of Industrial Economics, v. 6, n. 4, p. 606-620, 1981. Disponível em: <www.jstor.org/journals/aom.html> Acesso em: 9 jun. 2006.

LA PORTA, R.; LOPEZ-DE-SILANES, F. The benefits of privatization: evidence from México. NBER Working paper series. Oct. 1997. Disponível em: <http://papers. nber.org/papers/w6215.pdf ou SSRN: http://ssrn.com/abstract $=136948$ ou DOI: 10.2139/ssrn.136948 >. Acesso em: 19 nov. 2004.

LOPES, A.B.; ALENCAR, R. Disclosure and cost of equity capital in emerging markets: the Brazilian case. Working Paper. Disponível em: < http://papers.ssrn.com/>. Acesso em: 10 mar. 2008.

LOPES, Alexsandro Broedel; GALDI, Fernando Caio. Financial statement analysis also separate winners from losers in Brazil. In: SEMINÁRIO DE PESQUISA ECONÔMICA DA EFGE — FGV, 206, São Paulo. Anais... 
LOPES, A.B.; GALDI, F.C. Financial statement analysis generate abnormal returns under adverse conditions? In: ANNUAL MEETING OF THE AMERICAN ACCOUNTING ASSOCIATION, 2007, Chicago.

MARCON, R. O custo de capital próprio das empresas brasileiras: o caso das ADR's. Tese (doutorado em engenharia de produção) - Universidade Federal de Santa Catarina, Florianópolis, 2002.

MARKOWITZ, H.M. Portfolio selection. Journal of Finance, v. 7, n. 1, p. 77-91. Mar. 1952.

MARTINS, H.F. Reforma do Estado na era FHC: diversidade ou fragmentação da agenda de políticas de gestão pública. Tese (doutorado) - Escola Brasileira de Administração Pública e de Empresas, Fundação Getulio Vargas, Rio de Janeiro, 2004.

MATARAZZO, D.C. Análise financeira de balanços. 6. ed. São Paulo: Atlas, 2003.

MEGGINSON, W.L.; NETTER, J.M. From State to market: a survey of empirical studies on privatization. Journal of Economic Literature, v. 39, n. 2, June 2001. Disponível em: <http://ssrn.com/abstract $=262311$ ou DOI: $10.2139 /$ ssrn. $262311>$. Acesso em: 27 jul. 2005.

MELO, M.A. As agências reguladoras: gênese, desenho institucional e governança. In: ABRUCIO, F.L.; LOUREIRO, M.R. (Org.). O Estado numa era de reformas: os anos FHC. Brasília: Enap, 2002. (Gestão Pública)

MODIGLIANI, F.; MILLER, M. The Cost of Capital, Corporation Finance and the Theory of Investment. American Economic Review, v. 48, n. 3, p. 261-297, June 1958.

MOTA, Raffaella. The restructuring and privatisation of electricity distribution and supply businesses in Brazil: a social cost-benefit analysis. Working Paper, University of Cambridge, Cambridge, UK. 4 June 2003. Disponível em: <www.eletrobras.com. br/IN_Noticias_Biblioteca/crise.asp>. Acesso em: 20 set. 2008.

MYERS, S.C. The capital sctruture puzzle. The Journal of Finance, v. 39, n 3, p. 575-592, 1984.

NOSSA, Silvania Neris. A Recompra de ações e a análise fundamentalista: um estudo empírico na Bovespa no período de 1994 a 2006. Dissertação (mestrado em ciências contábeis) - Programa de Pós-Graduação em Ciências Contábeis, Fundação Instituto Capixaba de Pesquisas em Contabilidade, Economia e Finanças (Fucape), Vitória, 2007. 
PASTE, Fábio Lorenzoni. Análise do lucro e do risco das empresas exportadoras brasileiras versus empresas não exportadoras. Dissertação (mestrado em ciências contábeis) - Programa de Pós-Graduação em Ciências Contábeis, Fundação Instituto Capixaba de Pesquisas em Contabilidade, Economia e Finanças (Fucape), Vitória, 2006.

PECI, A. Modelos regulatórios na área de transportes: a experiência americana. In: CONGRESSO INTERNACIONAL DEL CLAD SOBRE LA REFORMA DEL ESTADO E DE LA ADMINISTRACIÓN PÚBLICA, 2002, Buenos Aires. Anais...

PECI, Alketa. Reforma regulatória brasileira dos anos 90 à luz do modelo de Kleber Nascimento. RAC, v. 11, n. 1, jan./mar. 2007.

PINHEIRO, A.C. Impactos microeconômicos da privatização no Brasil. Pesquisa e Planejamento Econômico, v. 26, n. 3, p. 357-397, 1996.

PIOTROSKI, J.D. Value investing: the use of historical financial statement information to separate winners from losers. Jornal of Accounting Research, v. 38, p. 1-41, 2000.

POMERLEANO, M.; ZHANH, X. Corporate fundamentals and the behavior of capital markets in Asia. In: HARWOOD, A.; LITAN, R.E.; POMERLEANO, M. Financial markets \& development: the crises in emerging markets. Washington: The Brookings Intitution, 1999. p. 117-157.

PORTER, M.E. Estratégia competitiva: técnicas para análise de indústrias e da concorrência. 7. ed. Rio de Janeiro: Campus, 1991.

REIS, R.M.M. Benefícios da privatização e reestruturação: evidência no setor de distribuição de energia elétrica no Brasil. Dissertação (mestrado em ciências contábeis) - Fundação Instituto Capixaba de Pesquisa em Contabilidade, Economia e Finanças (Funcape), Vitória, 2006.

ROSS, S.A.; WESTERFIELD, J.F.J.; JAFFE, F. Administração financeira. 2. ed. São Paulo: Atlas. 2002.

SALM, F.; CANDLER, G.G.; VENTRISS, C. The theory of social systems delimitation and the reconceptualization of public administration. Administrative Theory \& Praxis, v. 28, n. 4, p. 522-539, Nov./Dec. 2006.

SCHROEDER, J.T. et al. O custo de capital como taxa mínima de atratividade na avaliação de projetos de investimentos. Revista de Gestão Industrial, v. 1, n. 2, p. 36-45, 2005.

SERVA, M. Análise de empresas privatizadas: O desafio da multidimensionalidade. Civitas - Revista de Ciências Sociais, v. 3, n. 2, p. 349-373, 2003. 
SPICER, C. Public administration, the history of ideas, and the reinventing government movement. Public Administration Review, v. 64, p. 353-362, 2004.

SUTTON, John. Gibrat's Legacy. Journal of economic Literature, v. 35, n. 1, p. 4059, 1997. Disponível em: <www.jstor.org/journals/aom.html>. Acesso em: 9 jun. 2006.

TITMAN, S.; WESSELS, R. The determinants of capital structure choice. Journal of Finance, v. 43, n. 1, p. 1-19, 1988.

TORRES, Fernando. Senado dos EUA aprova pacote de US\$ 700 bi para setor financeiro. Jornal Valor Online. Disponível em: <www.valoronline.com.br/ValorOnLine/MateriaCompleta.aspx tit $=$ Senado + dos + EUA + aprova + pacote + de $+\mathrm{U}$ $\mathrm{S} \$+700+\mathrm{bi}+$ para + setor + financeiro $\&$ codmateria $=5181678 \&$ dtmateria $=02+10$ +2008 \&codcategoria $=38>$ Acesso em: 2 out. 2008.

VALOR ONLINE. Empresas pagam caro por recursos escassos. Disponível em: $<$ www.valoronline.com.br/ValorImpresso/MateriaImpresso.aspx?tit=Empresas $\% 20$ pagam $\% 20$ caro $\% 20$ por $\% 20$ recursos $\% 20$ escassos $\&$ dtMateria $=01 / 10 /$ 2008\&codMateria $=5179591 \& \operatorname{codCategoria}=83$ > . Acesso em: $1^{\circ}$ out. 2008.

VENTRISS, C. New public management: an examination of its influence on contemporary public affairs and its impact on shaping the intellectual agenda of the field. Administrative Theory \& Praxis, v. 22, p. 500-518, 2000.

VENTRISS, C. The need and relevance for public rationality: some critical reflections. Administrative Theory \& Praxis, v. 24, p. 287-298, 2002.

WATTS, R.L. Conservatism in accounting part I: explications and implications. Accounting Horizons, v. 17, n. 3, p. 207-221, Sept. 2003a.

WATTS, R.L. Conservatism in accounting part II: evidence and research opportunities. Accounting Horizons, v. 17, n. 4, p. 287-301, Dec. 2003b.

WILSON, J.Q. The politics of regulation. New York: Basic Books. 1980.

WOOLDRIDGE, J.M. Introdução à econometria: uma abordagem moderna. São Paulo: Pioneira Thomson Learning, 2006. 